${ }^{1}$ Department of Social Odontology, Legal Odontology Division, Piracicaba Dental School, University of Campinas, São Paulo, Brazil.

${ }^{2}$ Biostatistic of the post-graduation course from Paulista University, Brazil.

${ }^{3}$ Forensic Odontology Service, Afrânio Peixoto Legal Medicine Institute, Rio de Janeiro, Brazil.

Corresponding author: Luiz Francesquini Júnior Department of Social Odontology, Legal Odontology Division, Piracicaba Dental School, University of Campinas, Avenida Limeira, n 901, Bairro Areião, Piracicaba, SP, Brazil, CEP: 13414-903, Phone Number: +55 19 21065281, e-mail: francesq@unicamp.br

Editor: Dr Altair A. Del Bel Cury

Received: March 20, 2020

Accepted: March 6, 2021

\section{Evaluation of effectiveness of cranial morphological characteristics for sex estimation in a Brazilian sample}

\author{
Larissa Stasievski $^{1}$ (D) Viviane Ulbricht ${ }^{1} \mathbb{D}$, Vanessa \\ Gallego Arias Pecorari ${ }^{2}$ (D) Vanessa Moreira Andrade ${ }^{1,3}$ (D), \\ Luiz Francesquini Júnior ${ }^{1, *}$ (D)
}

Forensic physical anthropometry allows the determination of animal species and estimates sex, ancestry, age and height. Aim: To analyze the effectiveness of a cranioscopic/ morphological evaluation for sex estimation with a sample of the Brazilian mixed-race population by conducting a qualitative visual assessment without prior knowledge of sex. Methods: This is a blind cross-sectional study that evaluated 30 cranial characteristics of 192 skulls with mandible, 108 male and 84 female individuals, aged 22 to 97 years, from the Osteological and Tomographic Biobank. The qualitative characteristics were classified and compared to the actual sex information of the Biobank database. The statistical analysis was used to calculate de Cohen's kappa coefficient, total percentage of agreement, sensitivity and specificity of visual sex classification. Results: Of the 30 cranial variables analyzed, 15 presented moderate degree of agreement, achieving value of Kappa test between 0.41-0.60: Glabella(GI), Angleand lines (At), Mental eminence(Em), Mandible size ( $\mathrm{Tm})$, Cranial base (Bc), Mouth depth (Pb), Nasal aperture (Anl), Supraorbital region (Rs), Orbits (Orb), Mastoid processes $(\mathrm{Pm})$, Alveolar arches (Aa), Zygomatic arch (Az), Orbital edge (Bo), Supraorbital protuberances (Pts), and Supramastoid crests and rugosity (Crsm). The Facial physiognomy (Ff) presented substantial reliability (0.61-0.80) with $89.8 \%$ sensitivity for male sex and $70.2 \%$ specificity. Conclusions: Cranial morphological characteristics present sexual dimorphism; however, in this study only 15 variables showed moderate degree of agreement and can be used in sex estimation. Only one variable (Ff) 81.2\% total agreement with substantial reliability. Quantitative methods can be associated for safe sex estimation.

Keywords: Sex characteristics. Forensic anthropology. Skull. Mandible. 


\section{Introduction}

In an anthropological examination for forensic purposes, the determination of sex, species, ethnic group and estimated age and height are essential as such information help build an individual's biological profile ${ }^{1,2}$ and subsequent identification.

Musilová et al. ${ }^{2}$ (2016) e Durić et al. ${ }^{3}$ (2005) portrayed that the pelvis is the structure of the human skeleton that presents the highest degree of sexual dimorphism, being the most reliable bone for sex estimation. According to Musilová et al. ${ }^{2}$ (2016) the pelvis responds with evolutionary adaptation to bipedal locomotion and birth mechanisms, enabling parturition of children with relatively big brains.

But, in situations where the skeleton is not complete 4 or when the pelvis is not fully recovered, sex estimation can be achieved by performing a cranial analysis. As mentioned by Spradley and Jantz ${ }^{4}$ (2011), the skull has a high correct classification of sex, of 90-91\%.

In a skull examination, an anthropologist may use quantitative (metric) and/or qualitative (non-metric) methods $2,5,6$.

Lewis and Garvin (2016)7, Biancalana et al. (2015) ${ }^{8}$, Godde (2015)9 , Tallman and Go $(2018)^{10}$, Walker (2008) ${ }^{11}$ and Langley et al. (2018) ${ }^{12}$ are some authors which estimated the sex based on the skull morphology. This qualitative analysis is based on visual examination of the presence or degree of expression of morphological characteristics ${ }^{7}$, but despite its subjectivity ${ }^{8-11,13}$, may be the only possible method in cases of bone fragmentation ${ }^{7}$. An examination of non-metric traits also ensures an easy and fast analysis, without requiring any devices $7,10,12$.

In general, bone aspects such as prominences, crests and apophyses are more notable in men, while women have more delicate and less pronounced characteristics ${ }^{14}$.

Walker (2008)11 stated that the accuracy of sex determinations based on visual inspection depends on the osteologist's familiarity with the population being studied. And Franklin et al. (2013) ${ }^{15}$ mentioned that the forensic practitioner should access an osteological database for their specific geographic jurisdiction.

This changes in skull shape and size are population-specific ${ }^{11,15}$, and can be explained because each population is submitted to its own forces of evolution ${ }^{1,9,10}$. Environmental interventions $8^{8,10,15}$, nutritional status ${ }^{8,9}$, temporal changes ${ }^{8-12}$ and biomechanical processes related to neck, face and head movement ${ }^{9}$ can alter cranial morphological aspects, smoothing or enhancing the robustness of some characteristics.

In view of these situations, this study aimed to analyze the effectiveness of a cranioscopic/morphological evaluation (a qualitative visual assessment without prior knowledge of sex) with a sample of the Brazilian mixed-race population, for sex estimation.

\section{Materials and methods}

This study was approved by the Research Ethics Committee (CAAE $n^{\circ}$ 38522714.6.0000.5418).

The main sample consisted of 192 human skulls without alterations that impaired the analysis of morphological characteristics, 108 were male and 84 were female skulls, 
aged between 22 and 97 years, with median age of 57 years, from the Osteological and Tomographic Biobank. The year of death of this sample varied from 2006 to 2010.

The skulls of individuals who were 22 years or older at the time of their death were analyzed, excluding skulls of individuals who had not reached puberty as they show slightly pronounced qualitative characteristics, providing little information for sex estimation ${ }^{12,14}$.

All analyses were performed by a single rater. The researcher was previous calibrated analysing all the dichotomous variables (male or female) in 10 skulls, obtaining 100\% of consensual agreement between itself and a gold rater. The calibration has not been made through a statistical test. And the sample used for calibration was not included in the main sample.

Then the main sample of 192 skulls was evaluated, of which 30 cranial anatomical structures that were analyzed by this rater through visual inspection, using a non-metric method without prior knowledge of sex. Table 1 shows the morphological characteristics analyzed in this study.

Table 1. Morphological characteristics of skulls according to sex.

\begin{tabular}{|c|c|c|c|}
\hline Acronym & Description & Female & Male \\
\hline $\mathrm{Pe}$ & Weight & Less heavy & Heavier \\
\hline At & Angle and lines & Less angled, round and thin & $\begin{array}{l}\text { More angled and pronounced } \\
\text { lines }\end{array}$ \\
\hline lof & Frontal bone inclination & Vertical & Inclined \\
\hline Pts & Supraorbital protuberances & Level & Pronounced \\
\hline Rs & Supraorbital region & None to moderate & Medium to excessive \\
\hline $\mathrm{Gl}$ & Glabella & Flat and not very delimited & Prominent \\
\hline Bo & Orbital edge & Thin and sharp & Thick \\
\hline $\mathrm{Fc}$ & Canine fossa & Not very deep & Deep \\
\hline $\mathrm{Pm}$ & Mastoid processes & $\begin{array}{l}\text { Small, little protruding in } \\
\text { lower plane }\end{array}$ & $\begin{array}{l}\text { Robust, protruding in lower } \\
\text { plane }\end{array}$ \\
\hline Rcrm & $\begin{array}{l}\text { Condyle protuberance in } \\
\text { relation to the mastoid }\end{array}$ & With greater protuberance & Without greater protuberance \\
\hline Mcsp & $\begin{array}{l}\text { Skull movement on a flat } \\
\text { surface }\end{array}$ & $\begin{array}{l}\text { Does not move when } \\
\text { supported }\end{array}$ & Moves when supported \\
\hline $\mathrm{Sd}$ & Digastric groove & Not very deep and narrow & Deep and wide \\
\hline $\mathrm{Az}$ & Zygomatic arch & Thinner and shorter & More robust and wide \\
\hline Enl & Nasal spine & Less prominent & More prominent \\
\hline Anl & Nasal aperture & $\begin{array}{l}\text { Less tall and wide, with } \\
\text { rounded edges }\end{array}$ & $\begin{array}{c}\text { Taller and wider, with sharp } \\
\text { edges }\end{array}$ \\
\hline $\mathrm{Ff}$ & Facial physiognomy & Indicates female & Indicates male \\
\hline Orb & Orbits & Tall and round & Low and angular \\
\hline $\mathrm{Ct}$ & Temporal crests & Slightly marked & Marked \\
\hline Lns & Superior nuchal lines & Slightly marked & Marked \\
\hline Rpn & Nuchal plane surface & Slightly marked and smooth & Rough \\
\hline
\end{tabular}


continuation

\begin{tabular}{lccc}
\hline Crsm & $\begin{array}{c}\text { Supramastoid crests and } \\
\text { rugosity }\end{array}$ & Just perceptible & Marked \\
\hline $\mathrm{Aa}$ & Alveolar arches & Small & Raised \\
\hline $\mathrm{Td}$ & Tooth size & Smaller & Larger \\
\hline $\mathrm{Tm}$ & Mandible size & Smaller & Larger \\
\hline $\mathrm{Emd}$ & Mandible thickness & Smaller & Larger \\
\hline $\mathrm{Cm}$ & Mandibular condyles & Smaller & Larger \\
\hline $\mathrm{Am}$ & Mandibular angle & More obtuse & Straighter \\
\hline $\mathrm{Em}$ & Mental eminence & Pointed, rounded & Square \\
\hline $\mathrm{Pb}$ & Mouth depth & Narrow and not very deep & Larger and deeper \\
\hline $\mathrm{Bc}$ & Skull base & Level and delicate & Rough and strong \\
\hline
\end{tabular}

The visual analysis of all 30 variables generated a subjective differentiation between female and male skulls (nominal qualitative variable). Based on the knowledge of actual sex of the individuals, the degree of agreement was measured using Kappa test, considering the significance level $a=0.05$, the levels of strength of agreement measure by Cohen's kappa are interpreted as proposed by Landis and Koch ${ }^{16}$ (1977): almost perfect $(0.81-1.00)$, substantial $(0.61-0.80)$, moderate $(0.41-0.60)$, fair $(0.21-0.40)$, slight (0.00-0.20), or poor $(<0.00)$.

The percentage of correct sex was calculated using frequency tables (Crosstab) and the Cohen's kappa coefficient, total percentage of agreement, sensitivity, specificity visual sex classification were calculated. It was used SPSS Statistics version 25 statistical package (IBM Corporation, Chicago, USA) for data processing.

\section{Results}

The frequency and percentage of skull's real sex are described in Table 2 . The sample was relativily balanced with $56.3 \%$ of male and $43.8 \%$ female.

$32.8 \%$ of the sample consisted of skulls which age range was between 26-50 years old, $33.3 \%$ between $51-70$ years and $30.7 \%$ over 70 years old. And $96.5 \%$ of the skulls analysed presented the year of death 2010.

Table 2. Frequency and percentage of actual sex classification, range age and death's date of the skulls.

\begin{tabular}{lccc}
\hline \multirow{2}{*}{ Sample } & & \multicolumn{2}{c}{ Frequency } \\
\cline { 3 - 4 } Actual sex & & $\mathbf{n}$ & $\%$ \\
\hline & Female & 84 & 43.8 \\
\cline { 2 - 4 } & Male & 108 & 56.3 \\
\cline { 2 - 4 } Age range & $\leq 25$ & 6 & 3.1 \\
\cline { 2 - 4 } & 26 a 50 & 63 & 32.8 \\
\hline & 51 a 70 & 64 & 33.3 \\
\hline \multirow{3}{*}{ Death date } & over 70 & 59 & 30.7 \\
\cline { 2 - 4 } & 2006 & 6.5 & 3.1 \\
\cline { 2 - 4 } & 2009 & 185 & 96.4 \\
\hline
\end{tabular}


Due to the sample consisted of skulls aged older than 22 years, the authors performed the skull concordance tests without separating them by age.

Table 3 shows the frequency and percentage of sex classification based on a subjective analysis of different variables.

Through Kappa test, variables Pe $(k=0.08)$ and Ct $(k=-0.04)$, should not be used to determine sex, as they do not present statistical significance in the agreement test $(p>0.05)$.

Table 3. Frequency and percentage of sex classification based on a subjective rater analysis of different variables.

\begin{tabular}{|c|c|c|}
\hline & \multicolumn{2}{|c|}{ Sex } \\
\hline & $\begin{array}{l}\text { Male } \\
\text { N (\%) }\end{array}$ & $\begin{array}{l}\text { Female } \\
\mathrm{N}(\%)\end{array}$ \\
\hline $\mathrm{Pe}$ & $111(57.8)$ & $81(42.2)$ \\
\hline At & $117(60.9)$ & 75 (39.1) \\
\hline lof & $135(70.3)$ & 57 (29.7) \\
\hline Pts & $141(73.4)$ & $51(26.6)$ \\
\hline Rs & $136(70.8)$ & $56(29.2)$ \\
\hline $\mathrm{GI}$ & $123(64.1)$ & 69 (35.9) \\
\hline Bo & $108(56.3)$ & $84(43.8)$ \\
\hline Fc & 99 (51.6) & $93(48.4)$ \\
\hline $\mathrm{Pm}$ & $127(66.1)$ & 65 (33.9) \\
\hline Rcrm & $108(56.3)$ & $84(43.8)$ \\
\hline Mcsp & $77(40.1)$ & 115 (59.9) \\
\hline $\mathrm{Sd}$ & $104(54.2)$ & $88(45.8)$ \\
\hline $\mathrm{Az}$ & $88(45.8)$ & $104(54.2)$ \\
\hline Enl & $106(55.2)$ & $86(44.8)$ \\
\hline Anl & $125(65.1)$ & 67 (34.9) \\
\hline $\mathrm{Ff}$ & $122(63.5)$ & 70 (36.5) \\
\hline Orb & $141(73.4)$ & $51(26.6)$ \\
\hline $\mathrm{Ct}$ & $148(77.1)$ & $44(22.9)$ \\
\hline Lns & $152(79.2)$ & $40(20.8)$ \\
\hline Rpn & 151 (78.6) & $41(21.4)$ \\
\hline Crsm & $144(75.0)$ & $48(25.0)$ \\
\hline $\mathrm{Aa}$ & $96(50.0)$ & $96(50.0)$ \\
\hline $\mathrm{Td}$ & 69 (35.9) & $32(16.7)^{\star}$ \\
\hline $\mathrm{Tm}$ & $121(63.0)$ & 71 (37.0) \\
\hline Emd & $130(67.7)$ & 24 (32.3) \\
\hline $\mathrm{Cm}$ & 138 (71.9) & $54(28.1)$ \\
\hline Am & $106(55.2)$ & $86(44.8)$ \\
\hline Em & $98(51.0)$ & $94(49.0$ \\
\hline $\mathrm{Pb}$ & $132(68.7)$ & $60(31.3)$ \\
\hline $\mathrm{Bc}$ & $135(70.3)$ & $57(29.7)$ \\
\hline Actual sex & $108(56.3)$ & $84(43.8)$ \\
\hline
\end{tabular}

*Absent structures did not allow sex classification. 
Although the variable tooth size $(\mathrm{Td})$ has been visually analyzed, its statistical analysis was not made due to several skulls had no tooth.

The other variables showed statistically significant agreement from slight to fair level. Among these variables, Lns and Am had a slight level of agreement (0.00-0.20); Emd, lof, Cm, Mcsp, Enl, Fc, Rpn, Sd and Rcrm showed a fair level of agreement (0.21-0.40); Gl, At, Em, Tm, Bc, Pb, Anl, Rs, Orb, Pm, Aa, Az, Bo, Pts and Crsm presented a moderate level of agreement (0.41-0.60). And only Ff presented substantial level of agreement (0.61-0.80).

Table 4 shows the degree of agreement according to Kappa test and the p-value of all morphological variables, and the 16 variables with the best agreement degrees are highlighted with ${ }^{\dagger}$ symbol.

Table 4. Percentage of total agreement, Cohen's kappa coefficient and 95\% Cl kappa of variables in relation to actual sex.

\begin{tabular}{|c|c|c|c|}
\hline & Total agreement (\%) & Cohen's Kappa coefficient & IC 95\% Kappa \\
\hline $\mathrm{Pe}$ & 54.7 & 0.08 & $-0.06-0.217$ \\
\hline At & 81.7 & $0.60 *+$ & $0.49-0.72$ \\
\hline Iof & 71.4 & $0.40 *$ & $0.27-0.52$ \\
\hline Pts & 73.5 & $0.44^{* \dagger}$ & $0.31-0.56$ \\
\hline Rs & 76.1 & $0.49 *^{+}$ & $0.37-0.61$ \\
\hline $\mathrm{Gl}$ & 80.7 & $0.60 *+$ & $0.49-0.71$ \\
\hline Bo & 72.9 & $0.43^{*+}$ & $0.32-0.58$ \\
\hline Fc & 72.4 & $0.34 *$ & $0.21-0.47$ \\
\hline $\mathrm{Pm}$ & 73.4 & $0.45^{\star^{+}}$ & $0.32-0.58$ \\
\hline Rcrm & 62.5 & $0.24 *$ & $0.10-0.37$ \\
\hline Mcsp & 66.2 & $0.34 *$ & $0.21-0.46$ \\
\hline Sd & 65.6 & $0.30 *$ & $0.17-0.44$ \\
\hline $\mathrm{Az}$ & 72.9 & $0.46^{* \dagger}$ & $0.34-0.58$ \\
\hline Enl & 66.7 & $0.32 *$ & $0.20-0.46$ \\
\hline Anl & 75.5 & $0.49 *+$ & $0.37-0.61$ \\
\hline $\mathrm{Ff}$ & 81.2 & $0.61^{*^{+}}$ & $0.50-0.72$ \\
\hline Orb & 74.5 & $0.46^{* \dagger}$ & $0.34-0.58$ \\
\hline $\mathrm{Ct}$ & 51.1 & -0.04 & $-0.12-0.12$ \\
\hline Lns & 62.5 & $0.19 *$ & $0.07-0.31$ \\
\hline Rpn & 68.3 & $0.32 *$ & $0.19-0.44$ \\
\hline Crsm & 72.9 & $0.42^{\star^{\dagger}}$ & $0.30-0.54$ \\
\hline $\mathrm{Aa}$ & 74.0 & $0.48^{*+}$ & $0.36-0.60$ \\
\hline $\mathrm{Tm}$ & 77.6 & $0.54^{\star+}$ & $0.42-0.66$ \\
\hline Emd & 70.8 & $0.39 *$ & $0.26-0.52$ \\
\hline $\mathrm{Cm}$ & 70.9 & $0.38 *$ & $0.26-0.51$ \\
\hline Am & 59.4 & $0.18^{*}$ & $0.04-0.32$ \\
\hline $\mathrm{Em}$ & 79.1 & $0.58^{*^{+}}$ & $0.47-0.69$ \\
\hline $\mathrm{Pb}$ & 77.0 & $0.52^{*^{+}}$ & $0.40-0.64$ \\
\hline $\mathrm{Bc}$ & 76.6 & $0.51^{*+}$ & $0.40-0.62$ \\
\hline
\end{tabular}

*Indicates significance in the Kappa's test $(p<0.05)$;

${ }^{+}$Represent the variables with the best agreement degrees $(k>0.40)$. 
Table 5 shows the percentage of correct sex through Crosstab of 16 (sixteen) variables that presented statistically significant moderate and substantial agreement $(k>0.40 ; p<0.05)$. The visual sex classification of $F f, A t$ and $G$ l variables presented more than $80 \%$ of total agreement. The visual sex classification of Ff variable showed $89.8 \%$ sensitivity and $70.2 \%$ specificity for male sex classification. The At showed $87 \%$ sensitivity and $72.6 \%$ for male sex specificity and Gl showed $89.8 \%$ sensitivity and $69.0 \%$ specificity. The visual classification was more sensitivity for male sex, whereas for the female classification the sensitivity was lower.

Table 5. The sensitivity, specificity for visual sex classification of the variables that presented moderate and substantial reliability in Cohen's kappa coefficient $(k>0.40 ; p<0.05)$.

\begin{tabular}{|c|c|c|c|c|c|}
\hline & & & $\begin{array}{l}\text { Male } \\
\mathrm{N}(\%)\end{array}$ & $\begin{array}{c}\text { Female } \\
\mathrm{N}(\%)\end{array}$ & Total \\
\hline \multirow{2}{*}{$\mathrm{Gl}^{\#}$} & \multirow{2}{*}{ Actual sex } & Male & $97(89.8)^{\star}$ & $11(10.2)$ & $108(100.0)$ \\
\hline & & Female & $26(31.0)$ & $58(69.0)^{\dagger \ddagger}$ & $84(100.0)$ \\
\hline \multirow{2}{*}{$A t^{\#}$} & \multirow{2}{*}{ Actual sex } & Male & $94(87.0)^{\star}$ & $14(13.0)$ & $108(100.0)$ \\
\hline & & Female & $23(27.4)$ & $61(72.6)^{\dagger \ddagger}$ & $84(100.0)$ \\
\hline \multirow{2}{*}{$\mathrm{Ff}^{\#}$} & \multirow{2}{*}{ Actual sex } & Male & $97(89.8)^{\star}$ & $11(10.2)$ & $108(100.0)$ \\
\hline & & Female & $25(29.8)$ & $59(70.2)^{\dagger \ddagger}$ & $84(100.0)$ \\
\hline \multirow{2}{*}{$\mathrm{Em}^{\#}$} & \multirow{2}{*}{ Actual sex } & Male & $91(84.3)^{\star}$ & $17(15.7)$ & $108(100.0)$ \\
\hline & & Female & $39(46.4)$ & $45(53.6)^{\dagger \ddagger}$ & $84(100.0)$ \\
\hline \multirow{2}{*}{$\mathrm{Tm}$} & \multirow{2}{*}{ Actual sex } & Male & $93(86.1)^{\star}$ & 15 (13.9) & $108(100.0)$ \\
\hline & & Female & $28(33.3)$ & $56(66.7)^{\dagger \neq}$ & $84(100.0)$ \\
\hline \multirow{2}{*}{$\mathrm{Bc}$} & \multirow{2}{*}{ Actual sex } & Male & $99(91.7)^{\star}$ & $9(8.3)$ & $108(100.0)$ \\
\hline & & Female & $36(42.9)$ & $48(57.1)^{\dagger \ddagger}$ & $84(100.0)$ \\
\hline \multirow{2}{*}{$\mathrm{Pb}^{\#}$} & \multirow{2}{*}{ Actual sex } & Male & $98(90.7)^{\star}$ & $10(9.3)$ & $108(100.0)$ \\
\hline & & Female & $34(40.5)$ & $50(59.5)^{\dagger \ddagger}$ & $84(100.0)$ \\
\hline \multirow{2}{*}{ Anl } & \multirow{2}{*}{ Actual sex } & Male & $93(86.1)^{\star}$ & $15(13.9)$ & $108(100.0)$ \\
\hline & & Female & $32(38.1)$ & $52(61.9)^{\dagger \ddagger}$ & $84(100.0)$ \\
\hline \multirow{2}{*}{$\mathrm{Rs}^{\#}$} & \multirow{2}{*}{ Actual sex } & Male & $99(91.7)^{\star}$ & $9(8.3)$ & $108(100.0)$ \\
\hline & & Female & $37(44.0)$ & $47(56.0)^{\dagger \ddagger}$ & $84(100.0)$ \\
\hline \multirow{2}{*}{ Orb" } & \multirow{2}{*}{ Actual sex } & Male & $100(92.6)^{\star}$ & $8(7.4)$ & $108(100.0)$ \\
\hline & & Female & $41(48.8)$ & $43(51.2)^{\dagger \ddagger}$ & $84(100.0)$ \\
\hline \multirow{2}{*}{$\mathrm{Pm} \#$} & \multirow{2}{*}{ Actual sex } & Male & $92(85.2)^{\star}$ & $16(14.8)$ & $108(100.0)$ \\
\hline & & Female & 35 (41.7) & $49(58.3)^{\dagger \ddagger}$ & $84(100.0)$ \\
\hline \multirow{2}{*}{$\mathrm{Aa}$} & \multirow{2}{*}{ Actual sex } & Male & $77(71.3)^{\star}$ & 31 (28.7) & $108(100.0)$ \\
\hline & & Female & $19(22.6)$ & $65(77.4)^{\dagger \ddagger}$ & $84(100.0)$ \\
\hline \multirow{2}{*}{$A z$} & \multirow{2}{*}{ Actual sex } & Male & $72(66.7)^{\star}$ & 36 (33.3) & $108(100.0)$ \\
\hline & & Female & $16(19.0)$ & $68(81.0)^{\dagger \ddagger}$ & $84(100.0)$ \\
\hline \multirow{2}{*}{ Bo } & \multirow{2}{*}{ Actual sex } & Male & $82(75.9)^{\star}$ & $26(24.1)$ & $108(100.0)$ \\
\hline & & Female & $26(31.0)$ & $58(69.0)^{\dagger \ddagger}$ & $84(100.0)$ \\
\hline \multirow{2}{*}{ Pts $^{\#}$} & \multirow{2}{*}{ Actual sex } & Male & $99(91.7)^{\star}$ & $9(8.3)$ & $108(100.0)$ \\
\hline & & Female & $42(50.0)$ & $42(50.0)^{\text {tł }}$ & $84(100.0)$ \\
\hline
\end{tabular}


continuation

\begin{tabular}{|c|c|c|c|c|c|}
\hline \multirow{2}{*}{$\mathrm{Crsm}^{\#}$} & \multirow{2}{*}{ Actual sex } & Male & $100(92.6)^{*}$ & $8(7.4)$ & $108(100.0)$ \\
\hline & & Female & $44(52.4)$ & $40(47.6)^{\dagger \ddagger}$ & $84(100.0)$ \\
\hline
\end{tabular}

\# Represent the variables with the best results;

* Sensitivity to Male sex classification;

+ Specificity to Male sex classification;

$\ddagger$ Sensitivity to Female sex classification.

The variable Orb showed $92.6 \%$ sensitivity for male sex, however, $51.2 \%$ of specificity. The Ff, Gl and At were the variables with the highest index of sensitivity and specificity.

The percentages of correct sex for the 10 morphological variables with the best agreement degrees are highlighted with a hash in the same Table 5 and are presented in the Figure 1; all of them had higher percentages in the determination of male in relation to female sex, that is, such characteristics are more evident and facilitate identification in male sex.

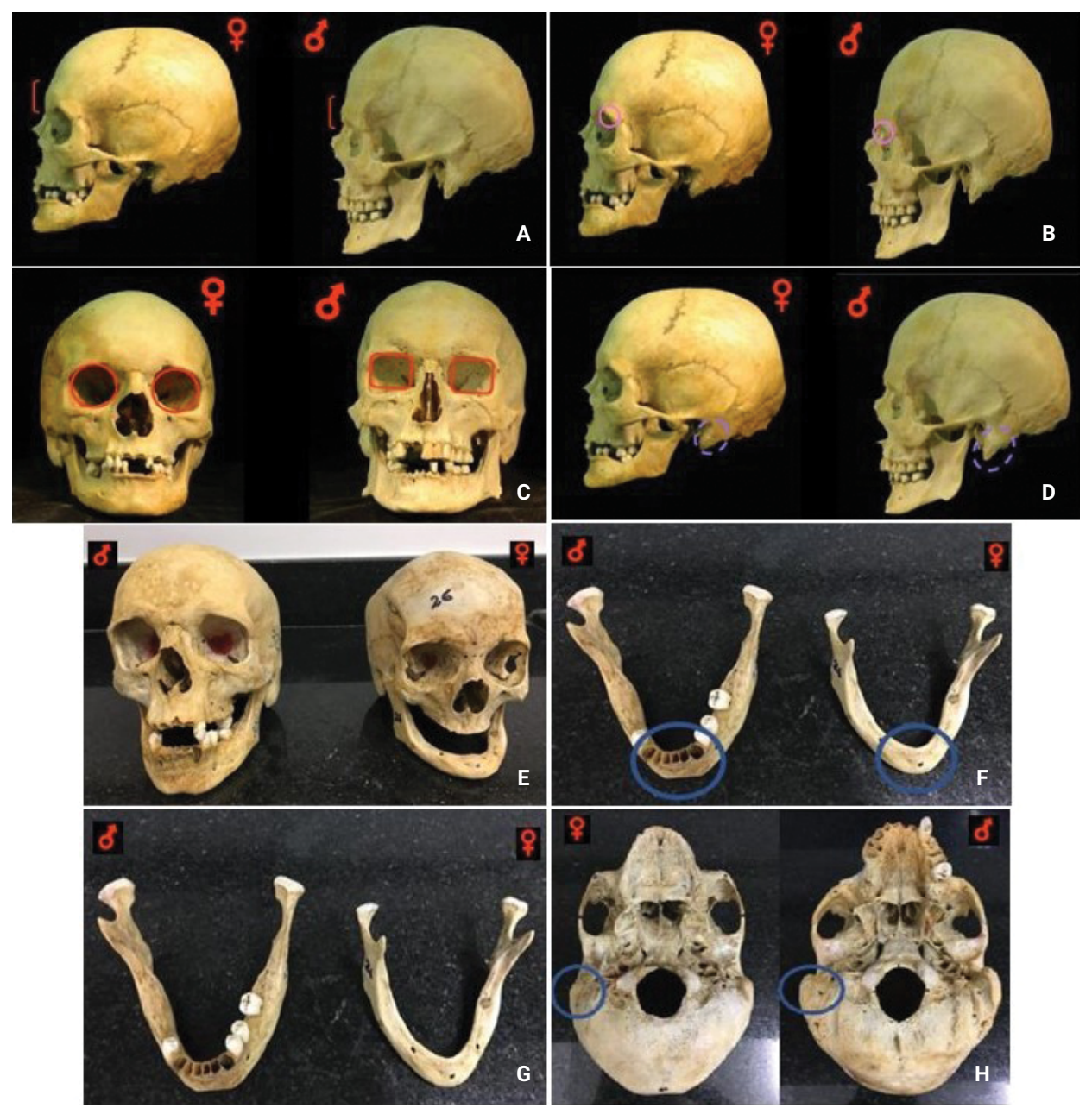

Figure 1. A: Glabella (GI); B: Supraorbital region (Rs) and Supraorbital protuberances (Pts); C: Orbits (Orb); $\mathrm{D}$ : Mastoid processes (Pm); E: Angle and lines (At) and Facial physiognomy (Ff); F: Mental eminence (Em); $\mathrm{G}$ : Mouth depth (Pb); H: Supramastoid crests and rugosity (Crsm). 


\section{Discussion}

In our study, using a balanced sample, although 30 cranial characteristics were analysed, only 15 variables achieved moderate agreement and one substantial agreement, but according to Cicchetti and Feinstein ${ }^{17}$ (1990) a low kappa can occur at a high agreement.

It is remarkable that age is a variable that can influence the quantitative measurement of bone size. However, the present study classified each skull qualitatively and the sample consisted of skulls aged older than 22 years, not dealing with the stage before puberty, between 10 and 21 yearsold which can be a confounding bias in the identification of the gender. For this reason, the skulls concordance tests were performed without separating them by age.

As the sex of all skulls was indexed in the Biobank, it was possible to estimate the percentage of correct sex for female and male population, which was not obtained in the study by Biancalana et al. ${ }^{8}$ (2015). Correct sex percentages for the 10 characteristics presenting the best agreement results were high, ranging from $47.6 \%$ to $92.6 \%$. Being observed that this qualitative classification is more sensitivity for male sex.

As observed in other studies $2,7,13,18,19$, glabella presented a high sexual dimorphism index, reaching $89.8 \%$ sensitivity and $69.0 \%$ of specificity for male sex classification, and a total agreement of $80.7 \%$.

In a qualitative analysis of the glabella region similar to ours, Abdel Fatah et al. ${ }^{13}(2014)$ and Walker ${ }^{11}$ (2008) found correct sex classification of $82 \%$ and $82.6 \%$, respectively.

Langley et al. ${ }^{12}$ (2018), when analyzing non-metric cranial traits, observed that mental eminence was the only variable that did not present a reasonable to moderate agreement for sex estimation, and should be avoided for such purpose. Low accuracy of $45.03 \%$ was also obtained in the study by Duric et al. ${ }^{3}$ (2005) for the size of mental eminence. In contrast, in our study, mental eminence was among the 10 best variables, with total agreement of $79.1 \%$, having $84.3 \%$ of sensitivity for male sex and $53.6 \%$ for female sex. Similarly, Lewis and Garvin (2016) and Walker ${ }^{11}$ (2008) found correct sex classification for this variable of $75.0 \%$ and $76.6 \%$, respectively.

In our study, regarding supraorbital protuberances (Pts), moderate agreement was observed (73.5\%), while Lewis and Garvin 7 (2016), when evaluating the eyebrow region, obtained $96.7 \%$ of correct sex classification.

Nikita and Michopoulou ${ }^{19}$ (2018) also analyzed the mastoid process profile and found for this variable, up to $75.2 \%$ and $74.5 \%$ correct classification for both sexes, similar to the percentages found by Walker ${ }^{11}$ (2008), while our study found for this characteristic, $85.2 \%$ of sensitivity for male sex and $58.3 \%$ for female sex.

In a study conducted by Graw et al. ${ }^{20}$ (1999), the analysis of the supraorbital margin shape allowed correct identification of sex, with about 70\% accuracy, an index that is similar to what was observed by Walker ${ }^{11}$ (2008), while Duric et al. ${ }^{3}$ (2005) reported sharpness of the supraorbital margins as the least reliable indicator with $28.75 \%$ accuracy only. Regarding orbits (Orb), our study showed the best percentage (92.6\%) of sensitivity for male sex. 
In a qualitative study conducted with European skulls, Williams and Rogers ${ }^{21}$ (2006) obtained high accuracy value for gonial angle (80.0\%), which do not agree with the results of our study, as the strength of agreement for that variable was slight with a Cohen's Kappa coefficient of 0.18 . In addition, the authors mentioned above ${ }^{20}$ reported orbit shape and position, and forehead inclination should not be considered as reliable variables for sex determination. In contrast, in our study, the orbits showed moderate strength of agreement with $74.5 \%$ of total agreement and frontal bone inclination presenting a fair level of strength of agreement with $71.4 \%$ of total agreement.

When analyzing jaw robustness, Durić et al. ${ }^{3}$ (2005) found high accuracy $(70.93 \%)$ for sex determination. In our study, mandible variables reached different agreements, such as mandible size (presenting moderate agreement), mandible thickness and mandibular condyles (fair agreement), and mandibular angle (slight agreement). Similarly, Keen ${ }^{22}$ (1950) reports that the angle of the mandible did not present a high index in sex differentiation.

In 2018, Tallman and Go ${ }^{10}$ evaluated Asian skulls, qualitatively analyzing nuchal crest, mastoid process, supraorbital margin, glabella and mental eminence, and obtaining $57.9 \%$ correct classification for female and $92.4 \%$ for male sex.

Similarly, was observed in our study that the visual classification of the cranial characteristics was more sensitivity for male sex. And to increase the probability of correct sex determination, we agree with Loth and Henneberg ${ }^{23}$ (1996) when they advise that a complete examination should be made of all available bones known to belong to an individual, combining qualitative and quantitative methodologies, to ensure improved certainty and reliability of forensic anthropological reports.

The percentages showed here are helpful for forensic practioners according to which preserved cranial trait is available in the skull that they are working on, and according to the population the skull is originated.

However, this study presents some limitations, as the analyses were performed by only one examiner, and although calibrated, by being a qualitative analysis it can be influenced by subjectivity, so the authors suggest that future studies use some examiners. Another limitation was common lighting and tables to analyze the skulls, being evaluated with the naked eye.

In conclusion, the visual classification of Ff variable presented the best sensitivity and specificity to male sex with substantial reliability. Next in decreasing order for the best qualitative evaluation of sex were the variables $\mathrm{Gl}, \mathrm{At}, \mathrm{Em}, \mathrm{Tm}, \mathrm{Bc}, \mathrm{Pb}$, Anl, Rs, Orb Pm, Aa, Az, Bo, Pts and Crsm which presented moderate agreement (41\% to $60 \%)$. The visual classification was more sensitivity for male sex. However, for improved certainty and reliability in sex estimation, quantitative methods are recommended.

\section{Acknowledgments}

The authors thank Espaço da Escrita/UNICAMP's General Coordination for the translation services provided. 


\section{References}

1. Krüger GC, L'Abbé EN, Stull KE, Kenyhercz MW. Sexual dimorphism in cranial morphology among modern South Africans. Int J Legal Med. 2015 Jul;129(4):869-75. doi: 10.1007/s00414-014-1111-0.

2. Musilová B, Dupej J, Velemínská J, Chaumoitre K, Bruzek J. Exocranial surfaces for sex assessment of the human cranium. Forensic Sci Int. 2016;269:70-7. doi: 10.1016/j.forsciint.2016.11.006.

3. Durić M, Rakocević Z, Donić $\mathrm{D}$. The reliability of sex determination of skeletons from forensic context in the Balkans. Forensic Sci Int. 2005;147(2-3):159-64.

4. Spradley MK, Jantz RL. Sex estimation in forensic anthropology: skull versus postcranial elements. J Forensic Sci. 2011;56(2):289-96. doi:10.1111/j.1556-4029.2010.01635.x.

5. Celbis O, Iscan MY, Soysal Z, Cagdir S. Sexual diagnosis of the glabellar region. Leg Med (Tokyo). 2001;3(3):162-70.

6. Ulbricht V, Schmidt CM, Groppo FC, Júnior ED, Queluz DP, Júnior LF. Sex Estimation in Brazilian Sample: Qualitative or Quantitative Methodology? Braz J Oral Sci. 2017;16:1-9. doi:10.20396/bjos.v16io.8650495.

7. Lewis CJ, Garvin HM. Reliability of the Walker Cranial Nonmetric Method and Implications for Sex Estimation. J Forensic Sci. 2016;61(3):743-51. doi:10.1111/1556-4029.13013.

8. Biancalana, RC, Ortiz AG, de Araújo LG, Semprini M, Galo R, Silva RHA. Determinação do sexo pelo crânio: etapa fundamental para a identificação humana. Rev. Bras. Crimin. 2015;4(3): 38-43.

9. Godde K. Secular trends in cranial morphological traits: a socioeconomic perspective of change and sexual dimorphism in North Americans 1849-1960. Ann Hum Biol. 2015;42(3):253-9. doi:10.3109/03014460.2014.941399.

10. Tallman SD, Go MC. Application of the Optimized Summed Scored Attributes Method to Sex Estimation in Asian Crania. J Forensic Sci. 2018;63(3):809-14. doi:10.1111/1556-4029.13644.

11. Walker PL. Sexing skulls using discriminant function analysis of visually assessed traits. Am J Phys Anthropol. 2008;136(1):39-50. doi:10.1002/ajpa.20776.

12. Langley NR, Dudzik B, Cloutier A. A Decision Tree for Nonmetric Sex Assessment from the Skull. J Forensic Sci. 2018;63(1):31-7. doi:10.1111/1556-4029.13534.

13. Abdel Fatah EE, Shirley NR, Jantz RL, Mahfouz MR. Improving sex estimation from crania using a novel three-dimensional quantitative method. J Forensic Sci. 2014;59(3):590-600. doi:10.1111/1556-4029.12379.

14. Francesquini Júnior L, Francesquini MA, De La Cruz BM, Pereira SD, Ambrosano GM, Barbosa CM, et al. Identification of sex using cranial base measurements. J Forensic Odontostomatol. 2007;25(1):7-11.

15. Franklin D, Cardini A, Flavel A, Kuliukas A. Estimation of sex from cranial measurements in a Western Australian population. Forensic Sci Int. 2013;229(1-3):158.e1-8. doi:10.1016/j.forsciint.2013.03.005.

16. Landis JR, Koch GG. The measurement of observer agreement for categorical data. Biometrics. 1977 Mar;33(1):159-74.

17. Cicchetti DV, Feinstein AR. High agreement but low kappa: II. Resolving the paradoxes. J Clin Epidemiol. 1990;43(6):551-8.

18. Garvin HM, Ruff CB. Sexual dimorphism in skeletal browridge and chinmorphologies determined using a new quantitative method. Am J Phys Anthropol. 2012;147(4):661-70. doi: 10.1002/ajpa.22036.

19. Nikita E, Michopoulou E. A quantitative approach for sex estimation based on cranial morphology. Am J Phys Anthropol. 2018;165(3):507-17. doi: 10.1002/ajpa.23376. 
20. Graw M, Czarnetzki A, Haffner HT. The form of the supraorbital margin as a criterion in identification of sex from the skull: investigations based on modern human skulls. Am J Phys Anthropol. 1999 Jan;108(1):91-6. doi: 10.1002/(SICI)1096-8644(199901)108:1<91::AID-AJPA5>3.0.CO;2-X.

21. Williams BA, Rogers T. Evaluating the accuracy and precision of cranial morphological traits for sex determination. J Forensic Sci. 2006;51(4):729-35.

22. Keen JA. A study of the differences between male and female skulls. Am J Phys Anthropol. 1950;8(1):65-79.

23. Loth SR, Henneberg M. Mandibular ramus flexure: a new morphologic indicator of sexual dimorphism in the human skeleton. Am J Phys Anthropol. 1996;99(3):473-85. 